\title{
Aging with HIV: what effect on mortality and loss to follow-up in the course of antiretroviral therapy? The leDEA West Africa Cohort Collaboration
}

This article was published in the following Dove Press journal:

HIVIAIDS - Research and Palliative Care

\begin{abstract}
Charlotte Bernard, ',2 Eric Balestre, ${ }^{1,2}$ Patrick A Coffie, ${ }^{3-5}$ Serge Paul Eholie, ${ }^{3,4}$ Eugène Messou, ${ }^{3-6}$ Viviane Kwaghe, ${ }^{7}$ Benson Okwara, ${ }^{8}$ Adrien Sawadogo, ${ }^{9}$ Yao Abo, ${ }^{10}$ François Dabis, ${ }^{1,2}$ Nathalie de Rekeneire $^{1,2}$

On behalf of the International Epidemiological Database to evaluate Aids (IeDEA) West Africa Collaboration

'INSERM, Centre INSERM UI219Epidémiologie-Biostatistique, Bordeaux, France; ${ }^{2}$ University of Bordeaux, School of Public Health (ISPED), Bordeaux, France; ${ }^{3}$ Département de Dermatologie et d'Infectiologie, UFR des Sciences Médicales, Université Félix Houphouët Boigny, Abidjan, Côte d'Ivoire; ${ }^{4}$ Unit of Infectious and Tropical Diseases, Treichville University Teaching Hospital, Abidjan, Côte d'Ivoire; ${ }^{5}$ Programme PAC-Cl, Treichville University Teaching Hospital, Abidjan, Ivory Coast; ${ }^{6}$ Center of Care, Research and Training (CePReF), Yopougon-Attié Hospital, Abidjan, Ivory Coast; ' ${ }^{7}$ niversity of Abuja Teaching Hospital, Abuja, Nigeria; ${ }^{8}$ University of Benin City Teaching Hospital, Benin City, Nigeria; ${ }^{\prime}$ Institut Supérieur des Sciences de la Santé (INSSA), Bobo-Dioulasso Polytechnic University, Bobo-Dioulasso, Burkina Faso; ${ }^{10} \mathrm{National}$ Blood Transfusion Center (CNTS), Abidjan, Ivory Coast
\end{abstract}

Correspondence: Charlotte Bernard Equipe Maladies Infectieuses DansLes Pays à Ressources Limitées-IDLIC, Centre INSERM UI219, ISPED, Université de Bordeaux, I46 Rue LéoSaignat, 33076 Bordeaux Cedex, France

Tel +33055 7575665

Fax +33055624008I

Email charlotte.bernard@u-bordeaux.fr
Background: Reporting mortality and lost to follow-up (LTFU) by age is essential as older HIV-positive patients might be at risk of long-term effects of living with HIV and/or taking antiretroviral therapy (ART). As age effects might not be linear and might impact HIV outcomes in the oldest more severely, people living with HIV (PLHIV) aged 50-59 years and PLHIV aged $>60$ years were considered separately.

Setting: Seventeen adult HIV/AIDS clinics spread over nine countries in West Africa.

Methods: Data were collected within the International Epidemiological Databases to Evaluate AIDS West Africa Collaboration. ART-naïve PLHIV-1 adults aged $>16$ years initiating ART and attending $\geq 2$ clinic visits were included $(\mathrm{N}=73,525)$. Age was divided into five groups: 16-29/30-39/40-49/50-59/ $\geq 60$ years. The age effect on mortality and LTFU was evaluated with Kaplan-Meier curves and multivariable Cox proportional hazard regressions.

Results: At month $36,5.9 \%$ of the patients had died and $47.3 \%$ were LTFU. Patients aged $\geq 60(\mathrm{~N}=1,736)$ and between $50-59$ years old $(\mathrm{N}=6,792)$ had an increased risk of death in the first 36 months on ART (adjusted hazard ratio=1.66; 95\% CI: 1.36-2.03 and adjusted hazard ratio $=1.31 ; 95 \%$ CI: $1.15-1.49$, respectively; reference: $<30$ years old). Patients $\geq 60$ years old tend to be more often LTFU.

Conclusion: The oldest PLHIV presented the poorest outcomes, suggesting that the PLHIV aged $>50$ years old should not be considered as a unique group irrespective of their age. Tailored programs focusing on improving the care services for older PLHIV in Sub-Saharan Africa are clearly needed to improve basic program outcomes.

Keywords: HIV, aging, ART, mortality, lost to follow-up, Sub-Saharan Africa

\section{Introduction}

According to The Joint United Nations Programme on HIV and AIDS (UNAIDS), 5.7 million people aged $\geq 50$ years were living with HIV in 2015 , a phenomenon that increased steadily since $1995 .{ }^{1}$ Sub-Saharan Africa (SSA) represents the region with the largest absolute number of older people living with HIV (PLHIV; 3.7 million). ${ }^{1}$ With the scaling up of antiretroviral therapy (ART), the efficacy of the last generation drugs, and the longer term follow-up in care, the life expectancy of the PLHIV has increased, and HIV disease is now considered as a chronic disease in most settings. Adding to this increased longevity pattern, new HIV diagnoses are raising among older adults as well.

Older African patients seem to have less knowledge and understanding of HIV infection and treatment in comparison with their younger counterparts. ${ }^{2}$ They are also 
often stigmatized and their conditions neglected. This could negatively impact their response to ART and their retention in care programs. Older patients present more advanced disease at ART initiation ${ }^{3}$ and have a poorer immunological response after 12 months of ART. ${ }^{4}$ They are also at higher risk of developing age-associated noncommunicable diseases, such as cardiovascular diseases, neurocognitive disorders, and frailty. ${ }^{5,6}$

Older PLHIV might thus be at greater risk of adverse ART outcomes and non-AIDS severe morbidity. Studying the longterm effect of age on mortality and lost to follow-up (LTFU) is essential in the current era of universal ART to document whether tailored HIV care management is needed in SSA.

Age effects on mortality and LTFU have indeed been less investigated, particularly in West Africa, than elsewhere in SSA. The majority of the data presented PLHIV aged $\geq 50$ years as a unique group but the effect of age might not be linear and might impact the HIV outcomes in the oldest more severely. The main objective of this study was to evaluate the effect of age on mortality and LTFU during the first 36 months after starting ART, among PLHIV older patients living in West Africa considering in two separate groups, PLHIV aged $50-59$ years and PLHIV aged $\geq 60$ years old and in comparison to younger patients.

\section{Materials and methods Study design}

Data collected between 2006 and 2016 within the International Epidemiological Databases to Evaluate AIDS (IeDEA) West Africa Collaboration of the US National Institutes of Health (https://www.iedea.org/regions/west-africa/) were analyzed. ${ }^{7}$ Since 2006, a network of adult and pediatric HIV clinics has been established in West Africa as part of the global IeDEA Collaboration. The aim of this multicenter collaboration is to get a fair description of the care and treatment patterns and their trends over time, collecting routine information on demographics, clinical, biological, and therapeutic skills. It currently involves 17 adult and 11 pediatric HIV/AIDS clinics spread over ten countries in West Africa: Benin, Burkina Faso, Cote d'Ivoire, Ghana, Guinea, Guinea Bissau, Mali, Nigeria, Senegal, and Togo. For this study, we conducted a multicenter, retrospective cohort analysis involving data from all the adult sites (except Ghana). All these centers participated on a voluntary basis.

Eligible patients were ART-naïve PLHIV-1 adults aged $\geq 16$ years who initiated ART, and attended $\geq 2$ clinic visits. Patients were excluded if the date of birth and the gender were not documented.

\section{Study definitions}

Mortality and LTFU were the primary outcomes. Mortality was defined as the number of deaths that occurred during that period. Death was recorded through reports by clinic staff, relatives, peers, or friends. LTFU was defined as no contact within 6 months before the cohort closure date and no knowledge of death or transfer. The database closing date corresponds to the date of the most recent follow-up visit.

For each patient, we documented the following: the CD4 cell count (cells by microliter) at ART initiation, the initial clinical stage using Centers for Disease Control and Prevention (CDC) or WHO definitions depending on the study sites (A/B/C or I/II/III/IV disease stages, respectively), the initial hemoglobin ( $\mathrm{Hb}$; low when $<7.5 \mathrm{~g} / \mathrm{dL}$ ), and the body mass index (BMI; low when $<18 \mathrm{~kg} / \mathrm{m}^{2}$ and high when $\geq 25 \mathrm{~kg} / \mathrm{m}^{2}$ ). The first-line ART regimen was also documented.

\section{Statistical analysis}

The effect of age at ART initiation on mortality and LTFU was investigated by dividing age into five age groups: 16-29, $30-39,40-49,50-59$, and $\geq 60$ years. The characteristics of the sample were described using median and interquartile range (IQR) for continuous variables and proportions for categorical variables according to age groups. Kaplan-Meier plots were produced by age groups to evaluate mortality and LTFU probabilities in the first 36 months after ART initiation, and compared using log-rank tests. To evaluate the risk of death after ART initiation, subjects who were LTFU were censored at the time of their last visit. Multivariable Cox proportional hazard regression analyses were performed to study the effect of age on mortality and LTFU as a predictor adjusted for the following baseline variables: clinical stage, $\mathrm{Hb}$ level, CD4 cell count and BMI, as well as year of ART initiation. HRs were reported with their 95\% CI. Statistical analyses were computed using SAS software 9.2 (SAS Institute Inc., Cary, NC, USA).

The IeDEA cohort's protocol has been approved by the national ethic committee of each participating country. All the patients gave their written consent or fingerprint if illiterate before being included in the cohort.

\section{Results}

\section{Patients' characteristics}

The vast majority (94\%) of the ART-naïve PLHIV in the IeDEA West Africa database were available for this analysis (Figure S1). Patients' characteristics at ART initiation are presented by age groups in Table 1 . 
Table I Baseline and follow-up characteristics of the PLHIV initiating ART by age $(\mathrm{N}=73,525)$

\begin{tabular}{|c|c|c|c|c|c|c|}
\hline & \multicolumn{5}{|l|}{ Age (years) } & \multirow{2}{*}{$\begin{array}{l}\text { Total } \\
\mathrm{N}=\mathbf{7 3 , 5 2 5}\end{array}$} \\
\hline & $\begin{array}{l}16-29 \\
N=16,458\end{array}$ & $\begin{array}{l}30-39 \\
N=29,968\end{array}$ & $\begin{array}{l}40-49 \\
N=|8,56|\end{array}$ & $\begin{array}{l}50-59 \\
N=6,792\end{array}$ & $\begin{array}{l}\geq 60 \\
N=1,736\end{array}$ & \\
\hline $\begin{array}{l}\text { Gender: female (\%) } \\
\text { Initial clinical stage (\%) }\end{array}$ & 86.3 & 68.6 & 51.1 & 47.8 & 50.9 & 65.8 \\
\hline WHO I/II or CDC A & 40.6 & 37.1 & 33.9 & 34.8 & 35.4 & 36.8 \\
\hline WHO III/IV or AIDS & 25.8 & 28.1 & 30.2 & 30.9 & 34.0 & 28.5 \\
\hline Missing & 33.6 & 34.8 & 35.9 & 34.3 & 30.6 & 34.7 \\
\hline Initial hemoglobin levela (g/dL) & $10.2[9.0-11.5]$ & $10.5[9.0-11.9]$ & $10.7[9.1-12.0]$ & $10.7[9.2-12.0]$ & $10.7[9.3-11.9]$ & $10.5[9.0-11.9]$ \\
\hline $\begin{array}{l}\text { Initial CD4 count } \text { cells } / \mu L) \\
\text { BMI }\left(\mathrm{kg} / \mathrm{m}^{2}\right)(\%)\end{array}$ & $\mid 85[8 \mid-307]$ & $167[7 \mid-278]$ & $160[68-27 \mid]$ & 175 [84-287] & $\mid 82[9 \mid-300]$ & $170[74-284]$ \\
\hline$<18$ & 12.7 & 10.5 & 10.2 & 10.7 & 10.8 & 11.0 \\
\hline $18-24.9$ & 31.0 & 32.5 & 32.0 & 32.5 & 29.0 & 32.0 \\
\hline$\geq 25$ & 7.2 & 9.5 & 10.4 & 10.1 & 8.9 & 9.2 \\
\hline Missing & 49.0 & 47.5 & 47.4 & 46.7 & 51.3 & 47.8 \\
\hline Year of ART initiation (\%) & & & & & & \\
\hline$<2007$ & 30.8 & 30.9 & 28.3 & 23.5 & 20.6 & 35.4 \\
\hline $2007-2010$ & 37.2 & 35.2 & 35.0 & 33.6 & 32.4 & 47.0 \\
\hline $2011-2015$ & 31.9 & 33.9 & 36.7 & 42.9 & 47.0 & 20.6 \\
\hline Follow-up duration ${ }^{a}$ (months) & $35.4[9.8-76.5]$ & $39.5[11.7-82.1]$ & $38.4[|1.5-8| .0]$ & $33.3[9.7-7 \mid .2]$ & $24.8[10.8-79.1]$ & $37.2[10.8-79.1]$ \\
\hline Death at 36 months (\%) & 3.7 & 3.9 & 4.7 & 5.9 & 6.9 & 4.3 \\
\hline Number of events & 613 & 1,182 & 872 & 402 & 120 & 3,189 \\
\hline LTFU at 36 months (\%) & 33.8 & 28.4 & 26.6 & 26.5 & 31.5 & 29.0 \\
\hline Number of events & 5,563 & 8,515 & 4,929 & I,802 & 546 & 21,355 \\
\hline
\end{tabular}

Note: Median [IQR].

Abbreviations: ART, antiretroviral therapy; BMI, body mass index; CDC, Centers for Disease Control and Prevention; IQR, interquartile range; LTFU, lost to follow-up; PLHIV, people living with HIV; WHO, World Health Organization.

Among the 73,525 patients included in this analysis, $1,736(2.4 \%)$ were aged $\geq 60$ years and $6,792(9.2 \%)$ were aged between 50 and 59 years. The median age was 36.5 years [IQR: $30.4-43.7]$. For $50-59$ and $\geq 60$ years age groups, the median age was 53.3 (IQR=51.3-55.7) and 63.6 (IQR=61.3-67.0), respectively. Women accounted for $65.8 \%$ of overall but the proportion of men increased with age (51.5\% among the 50-year old and above). A third of the patients aged $\geq 60$ years old ( $34 \%$ ) had advanced HIV disease (baseline clinical stage WHO III/IV or AIDS; overall sample: $28.4 \%$ ). The BMI was low for $11.0 \%$ whereas $9.2 \%$ had a high BMI. The median baseline $\mathrm{Hb}$ was $10.5 \mathrm{~g} / \mathrm{dL}$ [9.0-11.9] and the median initial CD4 count was 170 cells $/ \mu \mathrm{L}$ [74-284]. Nearly half of the patients aged $>60$ years old (47\%) started ART between 2011 and 2015.

\section{Age effect on mortality and LTFU probabilities}

The median follow-up time was 37.2 months [IQR: 10.779.1]. In the first 36 months after ART initiation, 4,302 $(5.9 \%)$ of the patients had died, and 34,742 (47.3\%) were LTFU. Significant differences were observed according to age groups ( $P<0.0001$ for both outcomes).
Patients aged $\geq 60$ years old and 50-59 years old showed the highest risk of death in the first year on ART: $5.55 \%$ (4.50-6.84) and 4.5\% (4.05-5.11), respectively. Then, the risk of death increased at $8 \%(6.67-9.60)$ and $6.21 \%(5.61-6.88)$ at 24 months, $9.06 \%(7.59-10.79)$ and $7.43 \%(6.75-8.18)$ at 36 months, respectively (Figure 1). For the other age groups, the risk of death remained under $6 \%$.

The oldest ( $\geq 60$ years old) presented the highest LTFU probability: $21.56 \%(19.63-23.65)$ at 12 months, $29.61 \%$ (27.38-31.98) at 24 months, and $36.74 \%(34.28-39.31)$ at 36 months. Patients between 50 and 59 years old presented an LTFU probability comparable to the middle-aged patients (about $30 \%$ at 36 months; Figure 2).

\section{Predictors of mortality and LTFU}

Multivariable Cox analyses for mortality and LTFU are presented in Tables 2 and 3, respectively. In these analyses, patients aged $\geq 60$ and 50-59 years had an increased risk of death (adjusted hazard ratio [aHR] $=1.66$; 95\% CI: 1.36-2.03 and aHR $=1.31 ; 95 \% \mathrm{CI}: 1.15-1.49$, respectively; reference [ref]: 16-29 years old). Also, male gender, advanced HIV disease, an initial CD4 less than 350 cell count $/ \mathrm{mm}^{3}$, an initial $\mathrm{Hb}<12 \mathrm{~g} / \mathrm{dL}$ (particularly when $\mathrm{Hb}<7.5 \mathrm{~g} / \mathrm{dL}$ ), or a $\mathrm{BMI}<18$ 


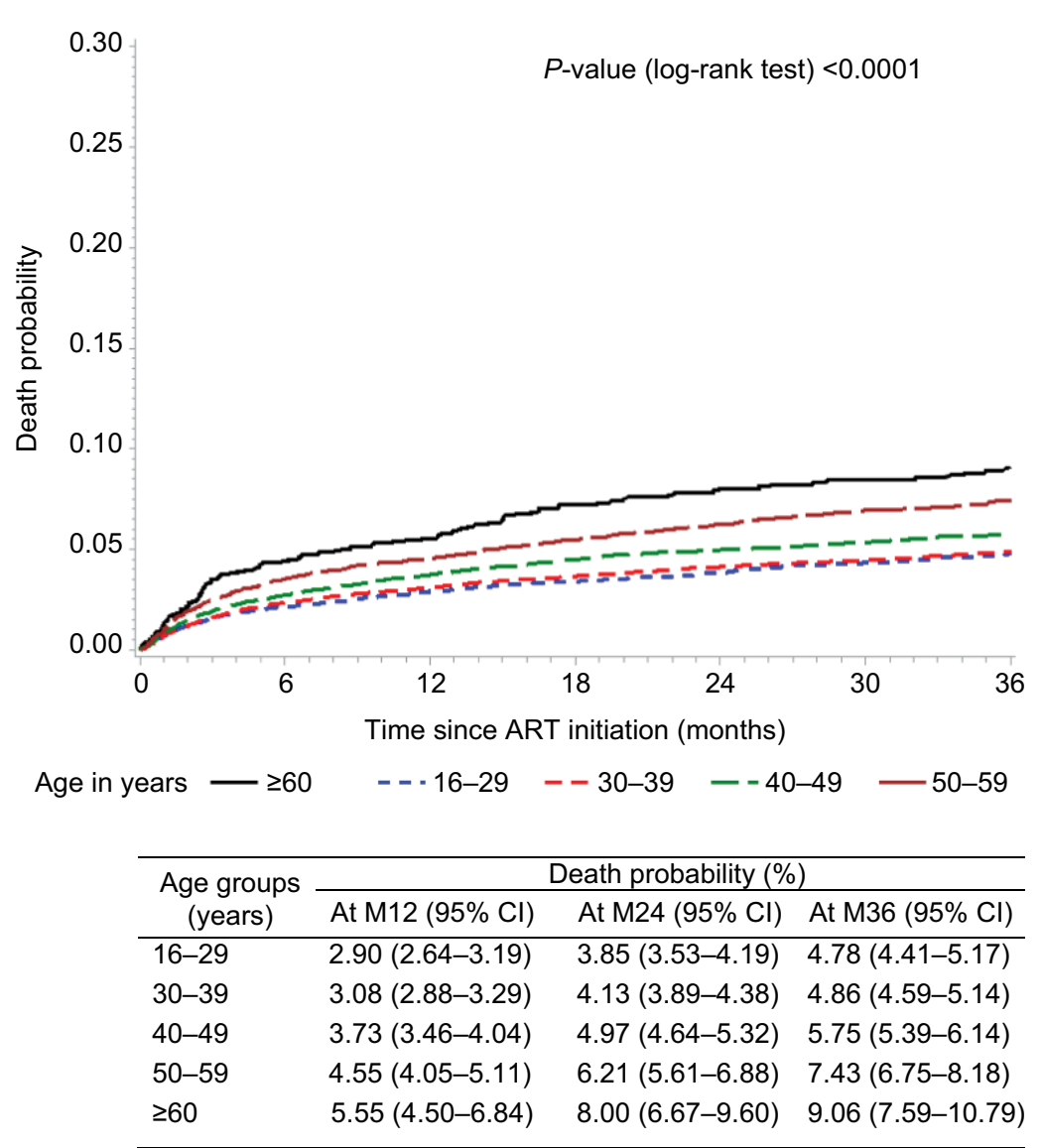

Figure I Probability of death (Kaplan-Meier estimate) after ART initiation by age groups.

Abbreviations: ART, antiretroviral therapy; MI2, 12 months; M24, 24 months; M36, 36 months.

$\mathrm{kg} / \mathrm{m}^{2}$ were all associated with an increased risk of death (all $P$-values $<0.0001$ ). Patients initiating ART in 2011 and after were more likely to die than those initiating ART before 2011 (aHR=1.79; 95\% CI: 1.61-1.99, ref: ART initiation<2007). Patients followed in facilities with large active lists of patients (1,000 and more) are less likely to die than those followed in smaller facilities $(<500$; aHR $=0.86$; 95\% CI: 0.77-0.97).

Concerning LTFU, middle-aged patients and patients between 50 and 59 years old were less likely to be LTFU after ART initiation than those in the $16-29$ age group ( $\mathrm{aHR}=0.78$; 95\% CI: $0.74-0.82$ for $50-59$ years old patients). Patients aged $>60$ years experienced comparable risks of LTFU than the 16-29 years age group ( $\mathrm{HR}=0.97$; 95\% CI: 0.88-1.06). Also, male gender, advanced HIV disease, an initial CD4 cell count $<100 / \mathrm{mm}^{3}$, an initial $\mathrm{Hb}<12 \mathrm{~g} / \mathrm{dL}$ (particularly when $\mathrm{Hb}<7.5 \mathrm{~g} / \mathrm{dL}$ ), or a BMI $<18 \mathrm{~kg} / \mathrm{m}^{2}$ were all associated with an increased risk of being LTFU (all $P<0.0001$ ). Patients initiating ART after 2011 were more likely to be LTFU than those initiating ART before 2007 (HR=1.63; 95\% CI: $1.57-1.69$, reference group ART initiation <2007). Patients followed in facilities with large active list of patients $(1,000$ and more) are less likely to be LTFU than those followed in smaller facilities $(<500$; aHR $=0.71$; 95\% CI: $0.68-0.74$, ref: $<500$ ). Performing separate Cox models in the $\geq 60$ years groups, we observed that HIV outcomes (disease stages and CD4 level) and the year of ART initiation are the main factors associated with LTFU. For the 50-59 years group, the results are similar (except for disease stages) whereas for the $<30$ years group, HIV outcomes seem not to be as relevant (year of ART initiation, hemoglobin, and BMI; Tables S1-S3).

\section{Discussion}

Being $\geq 50$ years at ART initiation was associated with an increased risk of death, and the excess risk was even stronger for $\geq 60$ years. Patients aged $\geq 60$ years old also presented a trend of higher risk of being LTFU in comparison with the other age groups. Beside age, being male and having poorer clinical conditions at ART initiation (advanced disease stage, lower CD4 count, lower $\mathrm{Hb}$ level, and low BMI) were also associated with these adverse outcomes; particularly for the 


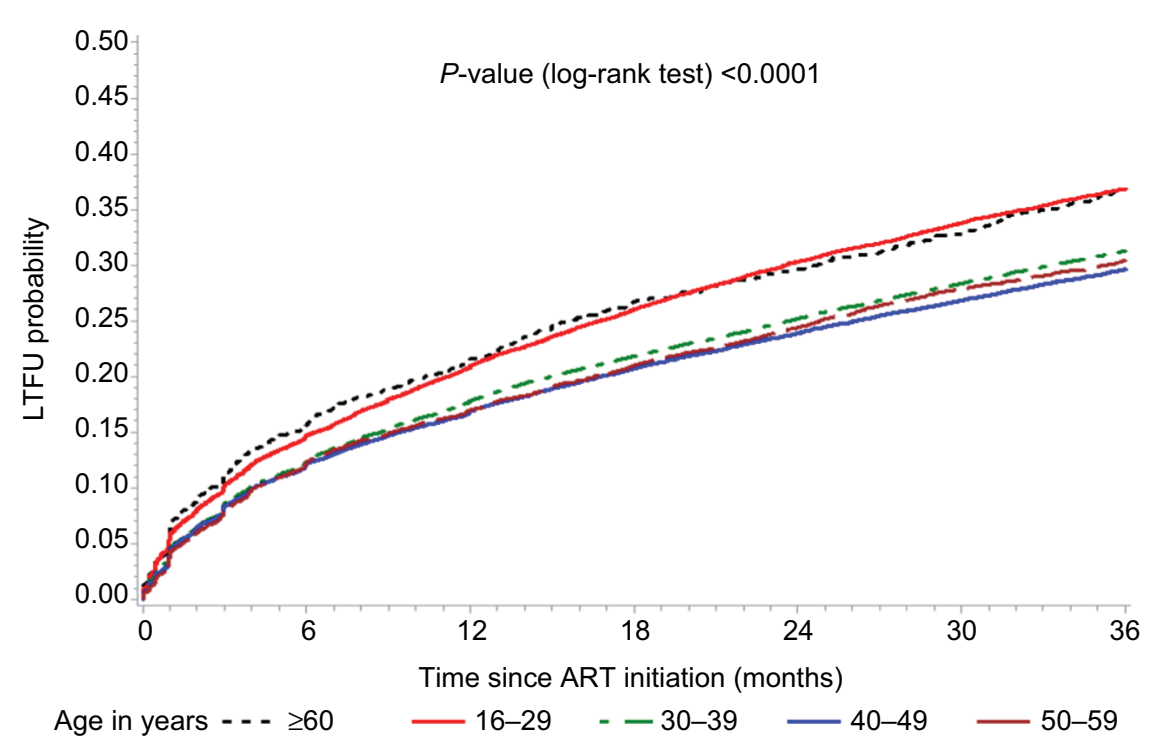

\begin{tabular}{lccc}
\hline \multirow{2}{*}{$\begin{array}{c}\text { Age groups } \\
\text { (years) }\end{array}$} & \multicolumn{3}{c}{ LTFU probability (\%) } \\
\cline { 2 - 4 } & At M12 $(95 \% \mathrm{Cl})$ & At M24 $(95 \% \mathrm{Cl})$ & At M36 (95\% Cl) \\
\hline $16-29$ & $20.94(20.31-21.58)$ & $30.33(29.60-31.06)$ & $36.85(36.08-37.64)$ \\
$30-39$ & $17.83(17.39-18.27)$ & $25.17(24.67-25.69)$ & $31.28(30.72-31.84)$ \\
$40-49$ & $16.90(16.36-17.46)$ & $23.88(23.25-24.53)$ & $29.61(28.91-30.32)$ \\
$50-59$ & $16.98(16.08-17.92)$ & $24.41(23.34-25.51)$ & $30.46(29.29-31.68)$ \\
$\geq 60$ & $21.56(19.63-23.65)$ & $29.61(27.38-31.98)$ & $36.74(34.28-39.31)$ \\
\hline
\end{tabular}

Figure 2 LTFU probability (Kaplan-Meier estimate) after ART initiation by age groups.

Abbreviations: ART, antiretroviral therapy; LTFU, lost to follow-up; MI2, 12 months; M24, 24 months; M36, 36 months.

oldest group, HIV outcomes seem to be the most specific factors associated with LTFU compared with other groups ( $<30$ and $50-59$ years groups).

The comparison of mortality patterns by age across studies remains difficult due to the use of different age categories as an explanatory variable. Our results are consistent with another study conducted in Cote d'Ivoire that assessed age as a continuous variable and was restricted to 18 months of follow-up. ${ }^{8}$ Another study used age as a dichotomous variable ( $<40$ or $\geq 40$ years old) and found an association with adverse outcomes within the first year of ART in Southern and West African countries combined. ${ }^{9}$ Other studies also reported a relationship between age at ART initiation and the probability of death within a 12-36 months follow-up period. ${ }^{10-13}$ Higher mortality in patients aged $>50$ or 55 years compared with patients $<50$ or 55 years, respectively, has also been observed with longer follow-up of 48-60 months..$^{14,15}$ When using age as a dichotomous variable ( $<50$ or $\geq 50$ years old), one study reported a significant higher probability of death in the older age group in the first 12 months after ART initiation whereas no significant difference was observed after this period, suggesting that in older patients, mortality is more likely due to a higher prevalence of non-HIV conditions such as cardiovascular diseases and diabetes. ${ }^{16}$ Baseline immunologic status seems to modify the effect of age on mortality since the strongest effect of age was observed among the patients with the lowest CD4 $(<50$ cells $/ \mu \mathrm{L})$ at ART initiation. ${ }^{10}$ In older PLHIV, presentation for care is often late, diagnosis is often delayed, and immune senescence and poorer CD4 immune reconstitution could explain this higher mortality risk. ${ }^{17-19}$

\section{Age and LTFU}

Patients between 50 and 59 years old experienced lower rates of LTFU compared with the youngest patients. The oldest one ( $\geq 60$ years) had a trend to having the highest risk of being LTFU. It should be acknowledged that an important part of LTFU could be due to an undernotification of death in this latter group, as the oldest PLHIV have a higher risk of death.

LTFU is a major reason to program losses in large public health HIV programs, as reported in South Africa. ${ }^{20}$ In African publications that included HIV patients aged $\geq 50$ years, a lower risk of being LTFU is often described in older patients 
Table 2 Predictors of death in the first 36 months after ART initiation (Cox models)

\begin{tabular}{|c|c|c|c|}
\hline \multirow[t]{2}{*}{ Variables } & \multirow{2}{*}{$\begin{array}{l}\text { Number } \\
\text { of deaths }\end{array}$} & \multicolumn{2}{|c|}{ Multivariable model } \\
\hline & & HR (95\% Cl) & $P$-value \\
\hline Age at ART initiation (years) & & & $<0.0001$ \\
\hline $16-29$ & 613 & I & \\
\hline $30-39$ & $\mathrm{I}, 182$ & $0.93(0.84-1.03)$ & \\
\hline $40-49$ & 872 & $1.02(0.91-1.13)$ & \\
\hline $50-59$ & 402 & $1.31(1.15-1.49)$ & \\
\hline$\geq 60$ & 120 & $1.66(1.36-2.03)$ & \\
\hline Gender & & & $<0.0001$ \\
\hline Female & $\mathrm{I}, 822$ & 1 & \\
\hline Male & $\mathrm{I}, 367$ & $1.41(1.30-1.52)$ & \\
\hline Year of ART initiation & & & $<0.0001$ \\
\hline$<2007$ & 1,096 & I & \\
\hline $2007-2010$ & $\mathrm{I}, 346$ & $1.37(1.25-1.5 \mathrm{I})$ & \\
\hline $20 I I$ and after & 747 & $1.79(1.61-1.99)$ & \\
\hline Initial clinical stage & & & $<0.0001$ \\
\hline A, B/I, II & 643 & I & \\
\hline AIDS/III, IV & $\mathrm{I}, 495$ & $1.91(1.74-2.1 \mathrm{I})$ & \\
\hline Missing & $\mathrm{I}, 05 \mathrm{I}$ & $\mathrm{I} .63(\mathrm{I} .46-\mathrm{I} .8 \mathrm{I})$ & \\
\hline 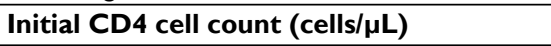 & & & $<0.0001$ \\
\hline$\geq 350$ & 120 & I & \\
\hline $200-349$ & 400 & $1.63(1.33-2.00)$ & \\
\hline $100-199$ & 610 & $2.37(1.94-2.89)$ & \\
\hline $50-99$ & 493 & $3.36(2.74-4.12)$ & \\
\hline $0-49$ & 1,053 & $5.02(4.14-6.09)$ & \\
\hline Missing & 513 & $2.92(2.38-3.59)$ & \\
\hline Initial hemoglobin (g/dL) & & & $<0.0001$ \\
\hline$\geq 12$ & 241 & I & \\
\hline $10-12$ & 559 & $1.30(1.12-1.52)$ & \\
\hline $7.5-10$ & 864 & $2.14(1.84-2.48)$ & \\
\hline$<7.5$ & 408 & $3.80(3.21-4.49)$ & \\
\hline Missing & $\mathrm{I}, \mathrm{II}$ & $0.76(0.65-0.88)$ & \\
\hline First ART regimen & & & 0.0010 \\
\hline $\mathrm{AZT}+3 \mathrm{TC} / \mathrm{FTC}+\mathrm{NVP} / \mathrm{EFV}$ & 815 & I & \\
\hline D4T+3TC/FTC+NVP/EFV & 903 & $1.20(1.08-1.33)$ & \\
\hline TDF+3TC/FTC+NVP/EFV & 723 & $1.16(1.04-1.29)$ & \\
\hline Others/unknown & 748 & $1.03(0.93-1.15)$ & \\
\hline BMI $\left(\mathbf{k g} / \mathrm{m}^{2}\right)$ & & & $<0.0001$ \\
\hline $18-25$ & 767 & 1 & \\
\hline$<18$ & 781 & $2.06(1.86-2.29)$ & \\
\hline$\geq 25$ & 102 & $0.64(0.52-0.79)$ & \\
\hline Missing & 1,539 & $1.82(1.64-2.02)$ & \\
\hline $\begin{array}{l}\text { Total number of patients started ART in } \\
2014-2015 \text { and still in care, in the facility }\end{array}$ & & & $<0.0001$ \\
\hline$<500$ & 747 & I & \\
\hline $500-1,000$ & 1,620 & $1.20(1.09-1.32)$ & \\
\hline$\geq 1,000$ & 822 & $0.86(0.77-0.97)$ & \\
\hline
\end{tabular}

Abbreviations: ART, antiretroviral therapy; BMI, body mass index.

in comparison with the youngest ones (16-29 years old in general). ${ }^{10,12,15,21-24}$ However, in a study including HIV patients from the IeDEA collaboration living in low-income countries in three continents, older age was associated with higher LTFU. ${ }^{25}$ Moreover, when classifying older age groups into two categories ( $\geq 60$ and $50-59$ years old), a nonsignificant trend of higher risk of being LTFU was observed among the oldest ones. ${ }^{11}$ Whereas young patients are more concerned with high mobility and work migration and are often dependent on others, the reasons being LTFU for the oldest might be different. ${ }^{15-22}$ Older patients may not want to impose the financial burden related to HIV care (transportation to clinics, treatment for other 
Table 3 Predictors of lost to follow-up in the first 36 months after ART initiation (Cox models)

\begin{tabular}{|c|c|c|c|}
\hline \multirow[t]{2}{*}{ Variables } & \multirow{2}{*}{$\begin{array}{l}\text { Number of lost to } \\
\text { follow-up }\end{array}$} & \multicolumn{2}{|c|}{ Multivariable model } \\
\hline & & HR (95\% Cl) & $P$-value \\
\hline Age at ART initiation (years) & & & $<0.0001$ \\
\hline $16-29$ & 5,563 & 1 & \\
\hline $30-39$ & 8,515 & $0.83(0.80-0.85)$ & \\
\hline $40-49$ & 4,929 & $0.76(0.73-0.79)$ & \\
\hline $50-59$ & I,802 & $0.78(0.74-0.82)$ & \\
\hline$\geq 60$ & 546 & $0.97(0.88-1.06)$ & \\
\hline Gender & & & $<0.0001$ \\
\hline Female & 13,465 & 1 & \\
\hline Male & 7,890 & $1.23(1.19-1.26)$ & \\
\hline Year of ART initiation & & & $<0.0001$ \\
\hline$<2007$ & 6,133 & 1 & \\
\hline $2007-2010$ & 7,100 & $1.01(0.98-1.05)$ & \\
\hline 2011 and after & 8,122 & $1.63(1.57-1.69)$ & \\
\hline Initial clinical stage & & & $<0.0001$ \\
\hline A, B/l, II & 6,847 & I & \\
\hline AIDS/III, IV & 5,377 & $1.12(1.08-1.17)$ & \\
\hline Missing & $9,|3|$ & $1.23(1.19-1.27)$ & \\
\hline Initial CD4 cell count (cells/ $\mu \mathrm{L})$ & & & $<0.0001$ \\
\hline$\geq 350$ & 2,640 & 1 & \\
\hline $200-349$ & 3,947 & $0.91(0.87-0.96)$ & \\
\hline $100-199$ & 3,810 & $0.96(0.91-1.01)$ & \\
\hline $50-99$ & 2,302 & $1.14(1.07-1.20)$ & \\
\hline $0-49$ & 3,436 & $1.30(1.23-1.37)$ & \\
\hline Missing & 5,220 & $1.00(0.95-1.05)$ & \\
\hline Initial hemoglobin (g/dL) & & & $<0.0001$ \\
\hline$\geq 12$ & $|, 43|$ & 1 & \\
\hline $10-12$ & 2,691 & $1.20(1.12-1.28)$ & \\
\hline $7.5-10$ & 2,528 & $1.42(1.33-1.52)$ & \\
\hline$<7.5$ & 707 & $1.64(1.50-1.80)$ & \\
\hline Missing & 13,998 & $1.46(1.38-1.55)$ & \\
\hline First ART regimen & & & $<0.000$ I \\
\hline $\mathrm{AZT}+3 \mathrm{TC} / \mathrm{FTC}+\mathrm{NVP} / \mathrm{EFV}$ & 5,617 & 1 & \\
\hline $\mathrm{D} 4 \mathrm{~T}+3 \mathrm{TC} / \mathrm{FTC}+\mathrm{NVP} / \mathrm{EFV}$ & 3,889 & $1.08(1.04-1.13)$ & \\
\hline TDF+3TC/FTC+NVP/EFV & 2,833 & $1.11(1.06-1.16)$ & \\
\hline Others/unknown & 9,016 & $1.38(1.33-1.44)$ & \\
\hline BMI $\left(\mathbf{k g} / \mathbf{m}^{2}\right)$ & & & $<0.0001$ \\
\hline $18-25$ & 4,855 & 1 & \\
\hline$<18$ & 1,950 & $1.19(1.13-1.26)$ & \\
\hline$\geq 25$ & 1,255 & $0.93(0.87-0.99)$ & \\
\hline Missing & 13,295 & $2.07(1.99-2.15)$ & \\
\hline Total number of patients started ART in & & & $<0.0001$ \\
\hline $2014-2015$ and still in care, in the facility & & & \\
\hline$<500$ & 8,081 & 1 & \\
\hline $500-1,000$ & 8,600 & $1.02(0.98-1.05)$ & \\
\hline$\geq 1,000$ & 4,674 & $0.71(0.68-0.74)$ & \\
\hline
\end{tabular}

Abbreviations: ART, antiretroviral therapy; BMI, body mass index.

associated comorbidities, etc.) to their family. ${ }^{25}$ Older PLHIV are also more likely to have comorbidities and cognitive decline, reasons which could explain LTFU..$^{15}$ Indeed, older patients with cognitive impairment had a 2.5 times greater risk of poor adherence, hence cognitive impairment, which increases with age, influences the commitment of the patient into care, so as polypharmacy ${ }^{26,27}$ Fear of stigma and discrimination could also explain the higher risk of being LTFU, as for the younger ones.

\section{Predictors of death and LTFU}

Poor nutrition (low BMI and low $\mathrm{Hb}$ level) has been associated with higher risk of mortality and LTFU early after ART 
initiation but also in the longer term. ${ }^{17,21,28-30}$ The association between advanced disease conditions at ART initiation (low CD4, AIDS stage) and higher probability of death or being LTFU has been largely observed. ${ }^{10,11,15-17,31-36}$ This seems to be the most important factor associated with LTFU in the oldest group.

In the context of the 90-90-90 objectives, PLHIV might start ART with less advanced HIV disease and thus their outcomes might be less pejorative. However, in practice, older adults are less likely questioned about their sexual practices than younger individuals and therefore might be diagnosed at a more advanced stage. ${ }^{19,37}$ Older patients receiving ART are also at an increased risk of age-associated noncommunicable comorbidities, like cardiovascular diseases, renal diseases, diabetes, cancers, osteoporosis, and neurocognitive impairment, which are often underdiagnosed but could influence treatment outcomes. ${ }^{5,6}$

In this context and the fact that with aging the immune system is less efficient and the immune response under ART is slower, older patients should be identified as a high-risk group needing specific clinical care. ${ }^{4,16}$

The probability of death and LTFU was associated with more recent ART initiation (>2011). This suggests that some clinics, particularly the smaller ones, might have difficulties to face the growing population of patients, to support the needed care for all those patients, and to trace the ones who are LTFU, particularly in the context of the 90-90-90 objectives. This has already been discussed elsewhere but for earlier years of ART initiation (before 2011). ${ }^{21,25}$ This is an important concern, since SSA is unprepared to deal with such an aging population. ${ }^{38,39}$ The risk of a significant burden on the health care systems and human resources needs to be considered.

\section{Limitations}

The main strength of the present study is the inclusion of multicenter data from 17 different sites from 9 West African countries, with a large sample size, including in the older group.

However, some limitations have to be mentioned. First, data were extracted from routine monitoring, leading to missing data, including for CD4 level, disease stage, viral load, and $\mathrm{Hb}$ level. The causes of death were not documented. Second, due to the retrospective nature of our data, information on other factors that can influence the probability of death or LTFU, such as economic status, social support, cognitive impairment, and depression was not available. In addition, ART adherence was not evaluated, and its impact on outcomes could not be investigated. Third, the reasons why patients were LTFU were not systematically collected, leading to an underestimation of the mortality risk and to an overestimation of LTFU, particularly in the oldest groups who are at higher risk of death. Based on a recent meta-analysis, mortality in LTFU African patients in ART programs ranged from $12 \%$ to $87 \% .{ }^{40}$ Finally, even the different ART services operating across West African settings (mostly in urban areas) are well represented in the collaboration, data from rural settings are also needed, thus limiting the generalizability of our results.

\section{Conclusion}

The present study emphasizes the importance of the older population in the HIV epidemic in West Africa and the need to adapt care to this key population. Particularly, the oldest HIV patients presented the highest risk of death, and more generally, aging with HIV was associated with poorer outcomes. Instead of considering older PLHIV as a unique group irrespective of their age, it would be interesting to consider differently patients aged 50-59 years old and patients $\geq 60$ years old. Tailored programs focused on improving the outcomes of older HIV patients in SSA are clearly needed, taking into account modifiable predictors and contribute to the achievement of the 90-90-90 objectives.

\section{Data availability}

Complete data for this study cannot be posted in a supplemental file or a public repository because of legal and ethical restrictions. The Principles of Collaboration under which the IeDEA multiregional collaboration was founded and the regulatory requirements of the different countries' Institutional Review Boards require the submission and approval of a project concept sheet by the IeDEA Executive Committee and the principal investigators from participating regions. All datasets provided by IeDEA are deidentified according to HIPAA Safe Harbor guidelines, with the exception of dates in some of the regions. Disclosure of a person's HIV status can be highly stigmatizing, and since reidentification of deidentified datasets may be possible when they are combined with publicly available datasets (see work of Dr Latanya Sweeney), IeDEA promotes the signing of a Data Use Agreement before HIV clinical data can be released. To request data, readers may contact IeDEA for consideration and instructions by filling out the online form available at www.iedea.org/home/who$\underline{\text { we-are and completing the application at www.iedea.org/ }}$ wp-content/uploads/2017/05/IeDEA Multiregional Concept_Application_Form_August_2016.docx. 


\section{Acknowledgments}

The IeDEA West Africa region: Site investigators and cohorts: Adult cohorts: Marcel Djimon Zannou, CNHU, Cotonou, Benin; Armel Poda, CHU Souro Sanou, Bobo Dioulasso, Burkina Faso; Fred Stephen Sarfo and Komfo Anokeye Teaching Hospital, Kumasi, Ghana; Eugene Messou, ACONDA CePReF, Abidjan, Cote d'Ivoire; Henri Chenal, CIRBA, Abidjan, Cote d'Ivoire; Kla Albert Minga, CNTS, Abidjan, Cote d'Ivoire; Emmanuel Bissagnene, and Aristophane Tanon, CHU Treichville, Cote d'Ivoire; Moussa Seydi, CHU de Fann, Dakar, Senegal; Akessiwe Akouda Patassi, CHU Sylvanus Olympio, Lomé, Togo. Pediatric cohorts: Sikiratou Adouni KoumakpaiAdeothy,_CNHU, Cotonou, Benin; Lorna Awo Renner, Korle Bu Hospital, Accra, Ghana; Sylvie Marie N'Gbeche, ACONDA CePReF, Abidjan, Ivory Coast; Clarisse Amani Bosse, ACONDA_MTCT+, Abidjan, Ivory Coast; Kouadio Kouakou, CIRBA, Abidjan, Cote d'Ivoire; Madeleine Amorissani Folquet, CHU de Cocody, Abidjan, Cote d'Ivoire; François Tanoh Eboua, CHU de Yopougon, Abidjan, Cote d'Ivoire; Fatoumata Dicko Traore, Hopital Gabriel Toure, Bamako, Mali; Elom Takassi, CHU Sylvanus Olympio, Lomé,Togo; Coordinators and data centers: François Dabis, Elise Arrive, Eric Balestre, Renaud Becquet, Charlotte Bernard, Shino Chassagne Arikawa, Alexandra Doring, Antoine Jaquet, Karen Malateste, Elodie Rabourdin, Thierry Tiendrebeogo, ADERA, Isped \& INSERM U1219, Bordeaux, France. Sophie Desmonde, Julie Jesson, Valeriane Leroy, Inserm 1027, Toulouse, France. Didier Koumavi Ekouevi, Jean-Claude Azani, Patrick Coffie, Abdoulaye Cissé, Guy Gnepa, Apollinaire Horo, Christian Kouadio, Boris Tchounga, PACCI, CHU Treichville, Abidjan, Côte d'Ivoire. This paper was presented at the IAS Conference in 2015 as a poster presentation with interim findings (Poster number: MoPeb153, title: Advancing in age: what effect on mortality and loss to follow-up in the course of aRT? The IeDea West Africa cohort collaboration).

The study was supported by the National Institute of Mental Health (NIMH), National Cancer Institute (NCI), the Eunice Kennedy Shriver National Institute of Child Health \& Human Development (NICHD), and the National Institute of Allergy and Infectious Diseases (NIAID) of the U.S. National Institutes of Health (NIH), as part of the International Epidemiologic Databases to Evaluate AIDS (IeDEA) under Award Number U01AI069919. The content is solely the responsibility of the authors and does not necessarily represent the official views of the National Institutes of Health.

\section{Disclosure}

The authors report no conflicts of interest in this work.

\section{References}

1. UNIAIDS. People living with HIV - People aged over 50 and over. Available from: http://aidsinfo.unaids.org/. 2016. Accessed November 08, 2018.

2. Negin J, Nemser B, Cumming R, Lelerai E, Ben Amor Y, Pronyk P. HIV attitudes, awareness and testing among older adults in Africa. AIDS Behav. 2012;16(1):63-68.

3. Martin CP, Fain MJ, Klotz SA. The older HIV-positive adult: a critical review of the medical literature. Am J Med. 2008;121(12):1032-1037.

4. Balestre E, Eholié SP, Lokossue A, et al. Effect of age on immunological response in the first year of antiretroviral therapy in HIV-1-infected adults in West Africa. AIDS. 2012;26(8):951-957.

5. Bendavid E, Ford N, Mills EJ. HIV and Africa's elderly: the problems and possibilities. AIDS Lond Engl. 2012;26(Suppl 1):S85-S91.

6. Schouten J, Wit FW, Stolte IG, et al. Cross-sectional comparison of the prevalence of age-associated comorbidities and their risk factors between HIV-infected and uninfected individuals: the AGEhIV cohort study. Clin Infect Dis. 2014;59(12):1787-1797.

7. Egger M, Ekouevi DK, Williams C, et al. Cohort Profile: the international epidemiological databases to evaluate AIDS (IeDEA) in subSaharan Africa. Int J Epidemiol. 2012;41(5):1256-1264.

8. Toure S, Kouadio B, Seyler C, et al. Rapid scaling-up of antiretroviral therapy in 10,000 adults in Côte d'Ivoire: 2-year outcomes and determinants. AIDS. 2008;22(7):873-882.

9. May M, Boulle A, Phiri S, et al. Prognosis of patients with HIV-1 infection starting antiretroviral therapy in sub-Saharan Africa: a collaborative analysis of scale-up programmes. Lancet. 2010;376(9739):449-457.

10. Cornell M, Johnson LF, Schomaker M, et al. Age in antiretroviral therapy programmes in South Africa: a retrospective, multicentre, observational cohort study. Lancet HIV. 2015;2(9):e368-e375.

11. Maskew M, Brennan AT, Macphail AP, Sanne IM, Fox MP. Poorer ART outcomes with increasing age at a large public sector HIV clinic in Johannesburg, South Africa. J Int Assoc Physicians AIDS Care. 2012;11(1):57-65.

12. Eduardo E, Lamb MR, Kandula S, et al. Characteristics and outcomes among older HIV-positive adults enrolled in HIV programs in four sub-Saharan African countries. PLoS One. 2014;9(7):e103864.

13. Greig J, Casas EC, O’Brien DP, Mills EJ, Ford N. Association between older age and adverse outcomes on antiretroviral therapy: a cohort analysis of programme data from nine countries. AIDS. 2012;26(Suppl 1):31-37.

14. Bakanda C, Birungi J, Mwesigwa R, et al. Association of aging and survival in a large HIV-infected cohort on antiretroviral therapy. AIDS. 2011;25(5):701-705.

15. Fatti G, Mothibi E, Meintjes G, Grimwood A. Antiretroviral treatment outcomes amongst older adults in a large multicentre cohort in South Africa. PLoS One. 2014;9(6):e100273.

16. Mutevedzi PC, Lessells RJ, Rodger AJ, Newell ML. Association of age with mortality and virological and immunological response to antiretroviral therapy in rural South African adults. PLoS One. 2011;6(7):e21795.

17. Gupta A, Nadkarni G, Yang WT, et al. Early mortality in adults initiating antiretroviral therapy (ART) in low- and middle-income countries (LMIC): a systematic review and meta-analysis. PLoS One. 2011;6(12):e28691.

18. Blanco JR, Caro AM, Pérez-Cachafeiro S, et al. HIV infection and aging. AIDS Rev. 2010;12(4):218-230.

19. Deeks SG. HIV infection, inflammation, immunosenescence, and aging. Annu Rev Med. 2011;62(1):141-155.

20. Cornell M, Grimsrud A, Fairall L, et al. Temporal changes in programme outcomes among adult patients initiating antiretroviral therapy across South Africa, 2002-2007. AIDS. 2010;24(14):2263-2270.

21. Asiimwe SB, Kanyesigye M, Bwana B, Okello S, Muyindike W. Predictors of dropout from care among HIV-infected patients initiating antiretroviral therapy at a public sector HIV treatment clinic in subSaharan Africa. BMC Infect Dis. 2016;16:43.

22. Megerso A, Garoma S, Eticha T, et al. Predictors of loss to follow-up in antiretroviral treatment for adult patients in the Oromia region, Ethiopia. HIV/AIDS. 2016;8:83-92. 
23. Meloni ST, Chang C, Chaplin B, et al. Time-dependent predictors of loss to follow-up in a large HIV treatment cohort in Nigeria. Open Forum Infect Dis. 2014;1(2):ofu055.

24. Vinikoor MJ, Joseph J, Mwale J, et al. Age at antiretroviral therapy initiation predicts immune recovery, death, and loss to follow-up among HIV-infected adults in urban Zambia. AIDS Res Hum Retroviruses. 2014;30(10):949-955.

25. Brinkhof MW, Dabis F, Myer L, et al. Early loss of HIV-infected patients on potent antiretroviral therapy programmes in lower-income countries. Bull World Health Organ. 2008;86(7):559-567.

26. Hinkin CH, Hardy DJ, Mason KI, et al. Medication adherence in HIVinfected adults: effect of patient age, cognitive status, and substance abuse. AIDS. 2004;18(Suppl 1):S19-S25.

27. Gleason LJ, Luque AE, Shah K. Polypharmacy in the HIV-infected older adult population. Clin Interv Aging. 2013;8:749-763.

28. Koethe JR, Lukusa A, Giganti MJ, et al. Association between weight gain and clinical outcomes among malnourished adults initiating antiretroviral therapy in Lusaka, Zambia. J Acquir Immune Defic Syndr. 2010;53(4):507-513.

29. Stringer JS, Zulu I, Levy J, et al. Rapid scale-up of antiretroviral therapy at primary care sites in Zambia: feasibility and early outcomes. JAMA. 2006;296(7):782.

30. Jerene D, Naess A, Lindtjørn B. Antiretroviral therapy at a district hospital in Ethiopia prevents death and tuberculosis in a cohort of HIV patients. AIDS Res Ther. 2006;3:10.

31. Castelnuovo B, Kiragga A, Musaazi J, et al. Outcomes in a cohort of patients started on antiretroviral treatment and followed up for a decade in an urban clinic in Uganda. PLoS One. 2015;10(12):e0142722.
32. Clouse K, Pettifor A, Maskew M, et al. Initiating antiretroviral therapy when presenting with higher CD4 cell counts results in reduced loss to follow-up in a resource-limited setting. AIDS. 2013;27(4):645-650.

33. Gabillard D, Lewden C, Ndoye I, et al. Mortality, AIDS-morbidity, and loss to follow-up by current CD4 cell count among HIV-1-infected adults receiving antiretroviral therapy in Africa and Asia: data from the ANRS 12222 collaboration. J Acquir Immune Defic Syndr. 2013;62(5):555-561.

34. Geng EH, Odeny TA, Lyamuya RE, et al. Estimation of mortality among HIV-infected people on antiretroviral treatment in East Africa: a sampling based approach in an observational, multisite, cohort study. Lancet HIV. 2015;2(3):e107-e116.

35. Negin J, van Lettow M, Semba M, Martiniuk A, Chan A, Cumming RG. Anti-retroviral treatment outcomes among older adults in Zomba district, Malawi. PLoS One. 2011;6(10):e26546.

36. Saka B, Landoh DE, Patassi A, et al. Loss of HIV-infected patients on potent antiretroviral therapy programs in Togo: risk factors and the fate of these patients. Pan Afr Med J. 2013;15:35.

37. Deeks SG. Immune dysfunction, inflammation, and accelerated aging in patients on antiretroviral therapy. Top HIV Med Publ Int AIDS Soc USA. 2009;17(4):118-123.

38. Mills EJ, Bärnighausen T, Negin J. HIV and aging-preparing for the challenges ahead. N Engl J Med. 2012;366(14):1270-1273.

39. Negin J, Bärnighausen T, Lundgren JD, Mills EJ. Aging with HIV in Africa: the challenges of living longer. AIDS. 2012;26(Suppl 1):S1-S5.

40. Brinkhof MW, Pujades-Rodriguez M, Egger M. Mortality of patients lost to follow-up in antiretroviral treatment programmes in resourcelimited settings: systematic review and meta-analysis. PLoS One. 2009;4(6):e5790. 


\section{Supplementary materials}

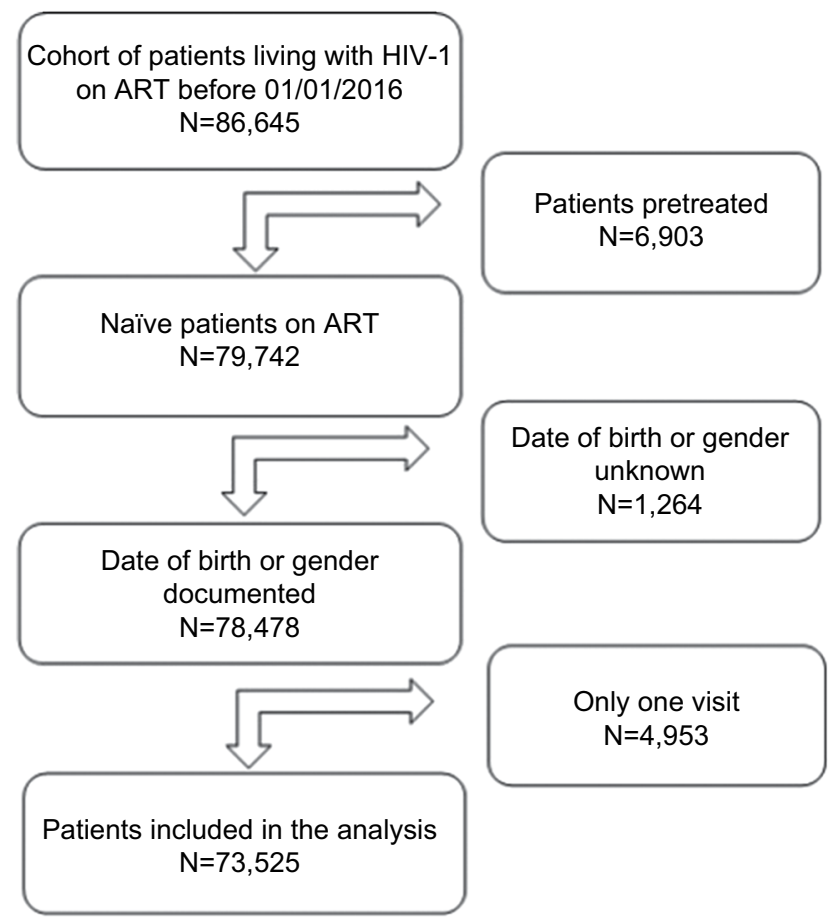

Figure SI Flowchart.

Table SI Effect of other factors (than age), on lost to follow-up in the first 36 months after ART initiation (Cox models), for patients $<30$ years while starting ART

\begin{tabular}{|c|c|c|c|c|c|}
\hline \multirow[t]{2}{*}{ Variables } & \multirow{2}{*}{$\begin{array}{l}\text { Number of lost } \\
\text { to follow-up }\end{array}$} & \multicolumn{2}{|c|}{ Univariable models } & \multicolumn{2}{|c|}{ Multivariable models } \\
\hline & & HR $(95 \% \mathrm{CI})$ & $P$-value & HR (95\% CI) & $P$-value \\
\hline Gender & & & $<0.0001$ & & $<0.0001$ \\
\hline Female & 4,719 & 1 & & 1 & \\
\hline Male & 844 & $1.22(1.14-1.32)$ & & $1.17(1.09-1.26)$ & \\
\hline Year of ART initiation & & & $<0.000$ I & & $<0.0001$ \\
\hline$<2007$ & 1,568 & 1 & & 1 & \\
\hline $2007-2010$ & 2,002 & $1.09(1.02-1.16)$ & & $1.06(0.99-1.13)$ & \\
\hline $20 \mathrm{II}$ and after & 1,993 & $1.62(1.52-1.73)$ & & $1.68(1.56-1.81)$ & \\
\hline Initial clinical stage & & & $<0.0001$ & & $<0.0001$ \\
\hline$A, B / I, I I$ & 1,989 & 1 & & 1 & \\
\hline AIDS/III,IV & 1,240 & $1.03(0.96-1.11)$ & & $1.10(1.02-1.18)$ & \\
\hline Missing & 2,334 & $1.55(1.46-1.64)$ & & $1.25(1.17-1.33)$ & \\
\hline Initial CD4 cell count (cells/ $\mu \mathrm{L})$ & & & $<0.0001$ & & $<0.0001$ \\
\hline$\geq 350$ & 968 & 1 & & 1 & \\
\hline $200-349$ & 1,129 & $0.71(0.65-0.77)$ & & $0.87(0.80-0.95)$ & \\
\hline $100-199$ & 970 & $0.68(0.63-0.75)$ & & $0.88(0.80-0.96)$ & \\
\hline $50-99$ & 538 & $0.84(0.76-0.93)$ & & $1.03(0.92-1.15)$ & \\
\hline $0-49$ & 809 & $0.93(0.84-1.02)$ & & $1.13(1.02-1.24)$ & \\
\hline Missing & 1,149 & $0.81(0.75-0.89)$ & & $0.83(0.76-0.91)$ & \\
\hline Initial hemoglobin (g/dL) & & & $<0.0001$ & & $<0.000$ I \\
\hline$\geq 12$ & 288 & 1 & & 1 & \\
\hline $10-12$ & 668 & $1.08(0.94-1.24)$ & & $1.07(0.93-1.23)$ & \\
\hline $7.5-10$ & 575 & $1.19(1.03-1.37)$ & & $1.15(0.99-1.33)$ & \\
\hline$<7.5$ & 182 & $1.61(1.34-1.94)$ & & $1.44(1.19-1.74)$ & \\
\hline Missing & 3,850 & $1.48(1.31-1.67)$ & & $1.24(1.10-1.41)$ & \\
\hline
\end{tabular}

(Continued) 
Table SI (Continued)

\begin{tabular}{|c|c|c|c|c|c|}
\hline \multirow[t]{2}{*}{ Variables } & \multirow{2}{*}{$\begin{array}{l}\text { Number of lost } \\
\text { to follow-up }\end{array}$} & \multicolumn{2}{|c|}{ Univariable models } & \multicolumn{2}{|c|}{ Multivariable models } \\
\hline & & HR (95\% Cl) & $P$-value & HR (95\% Cl) & $P$-value \\
\hline First ART regimen & & & $<0.0001$ & & $<0.0001$ \\
\hline $\mathrm{AZT}+3 \mathrm{TC} / \mathrm{FTC}+\mathrm{NVP} / \mathrm{EFV}$ & 1,316 & 1 & & 1 & \\
\hline $\mathrm{D} 4 \mathrm{~T}+3 \mathrm{TC} / \mathrm{FTC}+\mathrm{NVP} / \mathrm{EFV}$ & 863 & $0.85(0.78-0.92)$ & & $0.98(0.89-1.07)$ & \\
\hline TDF+3TC/FTC+NVP/EFV & 608 & $1.28(1.16-1.40)$ & & $1.08(0.97-1.19)$ & \\
\hline Others/unknown & 2,776 & $1.57(1.47-1.68)$ & & $1.31(I .2 I-1.4 I)$ & \\
\hline BMI $\left(\mathbf{k g} / \mathbf{m}^{2}\right)$ & & & $<0.000$ I & & $<0.000$ I \\
\hline $18-25$ & 1,235 & 1 & & I & \\
\hline$<18$ & 572 & $1.24(1.12-1.37)$ & & $1.18(\mid .07-1.31)$ & \\
\hline$\geq 25$ & 261 & $0.87(0.76-0.99)$ & & $0.88(0.77-1.01)$ & \\
\hline Missing & 3,495 & $2.14(2.01-2.29)$ & & $2.04(1.89-2.20)$ & \\
\hline Total number of patients started ART in & & & $<0.0001$ & & $<0.0001$ \\
\hline $2014-2015$ and still in care, in the facility & & & & & \\
\hline$<500$ & 2,673 & 1 & & I & \\
\hline $500-1000$ & 2,038 & $0.71(0.67-0.76)$ & & $1.09(1.01-1.17)$ & \\
\hline$\geq 1000$ & 852 & $0.77(0.72-0.84)$ & & $0.67(0.6 \mathrm{I}-0.73)$ & \\
\hline
\end{tabular}

Abbreviations: ART, antiretroviral therapy; BMI, body mass index.

Table S2 Effect of other factors (than age), on lost to follow-up in the first 36 months after ART initiation (Cox models), for patients 50-59 years while starting ART

\begin{tabular}{|c|c|c|c|c|c|}
\hline \multirow[t]{2}{*}{ Variables } & \multirow{2}{*}{$\begin{array}{l}\text { Number of lost } \\
\text { to follow-up }\end{array}$} & \multicolumn{2}{|c|}{ Univariable models } & \multicolumn{2}{|c|}{ Multivariable models } \\
\hline & & HR (95\% Cl) & $P$-value & HR (95\% Cl) & $P$-value \\
\hline Gender & & & $<0.0001$ & & 0.0014 \\
\hline Female & 780 & 1 & & I & \\
\hline Male & 1,022 & $1.24(1.13-1.36)$ & & $1.17(1.06-1.29)$ & \\
\hline Year of ART initiation & & & $<0.0001$ & & $<0.000$ I \\
\hline$<2007$ & 454 & 1 & & I & \\
\hline $2007-2010$ & 554 & $0.86(0.76-0.97)$ & & $0.93(0.82-1.06)$ & \\
\hline $201 \mathrm{I}$ and after & 794 & $1.27(1.13-1.43)$ & & $1.46(1.28-1.67)$ & \\
\hline Initial clinical stage & & & $<0.0001$ & & 0.01 \\
\hline $\mathrm{A}, \mathrm{B} / \mathrm{I}, \mathrm{II}$ & 539 & I & & I & \\
\hline AIDS/III,IV & 489 & $1.08(0.96-1.23)$ & & $1.12(0.99-1.27)$ & \\
\hline Missing & 774 & $1.50(1.34-1.67)$ & & $1.20(1.07-1.35)$ & \\
\hline Initial CD4 cell count (cells/ $\mu \mathrm{L})$ & & & $<0.0001$ & & $<0.0001$ \\
\hline$\geq 350$ & 172 & 1 & & I & \\
\hline $200-349$ & 326 & $0.94(0.78-1.13)$ & & I.0I (0.84-I.22) & \\
\hline $100-199$ & 334 & $1.06(0.88-1.27)$ & & $1.16(0.96-1.40)$ & \\
\hline $50-99$ & 205 & $1.45(1.19-1.78)$ & & $1.48(1.20-1.82)$ & \\
\hline $0-49$ & 251 & $\mathrm{I} .54(\mathrm{I} .27-\mathrm{I} .87)$ & & $1.51(1.24-1.85)$ & \\
\hline Missing & 514 & $1.52(1.28-1.81)$ & & $1.28(1.06-1.54)$ & \\
\hline Initial hemoglobin (g/dL) & & & $<0.0001$ & & 0.0007 \\
\hline$\geq 12$ & 170 & I & & I & \\
\hline $10-12$ & 243 & I.03 (0.84-I.25) & & $1.02(0.83-1.24)$ & \\
\hline $7.5-10$ & 250 & $1.56(1.29-1.90)$ & & $1.39(I . \mid 4-1.7 I)$ & \\
\hline$<7.5$ & 56 & $1.76(1.30-2.39)$ & & $1.41(1.03-1.92)$ & \\
\hline Missing & 1,083 & $1.46(1.25-1.72)$ & & $1.26(1.05-1.50)$ & \\
\hline First ART regimen & & & $<0.0001$ & & 0.001 \\
\hline $\mathrm{AZT}+3 \mathrm{TC} / \mathrm{FTC}+\mathrm{NVP} / \mathrm{EFV}$ & 561 & 1 & & I & \\
\hline $\mathrm{D} 4 \mathrm{~T}+3 \mathrm{TC} / \mathrm{FTC}+\mathrm{NVP} / \mathrm{EFV}$ & 331 & $0.98(0.86-1.13)$ & & $1.04(0.90-1.21)$ & \\
\hline TDF+3TC/FTC+NVP/EFV & 299 & $1.18(1.03-1.36)$ & & $1.02(0.88-1.18)$ & \\
\hline Others/unknown & 611 & $1.53(1.37-1.72)$ & & $1.27(1.12-1.44)$ & \\
\hline
\end{tabular}


Table S2 (Continued)

\begin{tabular}{|c|c|c|c|c|c|}
\hline \multirow[t]{2}{*}{ Variables } & \multirow{2}{*}{$\begin{array}{l}\text { Number of lost } \\
\text { to follow-up }\end{array}$} & \multicolumn{2}{|c|}{ Univariable models } & \multicolumn{2}{|c|}{ Multivariable models } \\
\hline & & HR (95\% Cl) & $P$-value & HR (95\% Cl) & P-value \\
\hline BMI $\left(\mathbf{k g} / \mathrm{m}^{2}\right)$ & & & $<0.0001$ & & $<0.0001$ \\
\hline $18-25$ & 434 & 1 & & I & \\
\hline$<18$ & 159 & $1.28(1.07-1.54)$ & & I. $18(0.98-1.4 I)$ & \\
\hline$\geq 25$ & 113 & $0.81(0.66-0.99)$ & & $0.87(0.7 \mathrm{I}-\mathrm{I} .07)$ & \\
\hline Missing & 1,096 & $2.06(1.85-2.31)$ & & $2.07(1.82-2.36)$ & \\
\hline Total number of patients started ART in 2014- & & & $<0.0001$ & & $<0.0001$ \\
\hline 2015 and still in care, in the facility & & & & & \\
\hline$<500$ & 485 & I & & I & \\
\hline $500-1000$ & 811 & $0.76(0.68-0.85)$ & & $0.91(0.81-1.03)$ & \\
\hline$\geq 1000$ & 506 & $0.99(0.87-I . \mid 2)$ & & $0.68(0.59-0.78)$ & \\
\hline
\end{tabular}

Abbreviations: ART, antiretroviral therapy; BMI, body mass index.

Table S3 Effect of others factor (than age), on lost to follow-up in the first 36 months after ART initiation (Cox models), for patients $>60$ years while starting ART

\begin{tabular}{|c|c|c|c|c|c|}
\hline \multirow[t]{2}{*}{ Variables } & \multirow{2}{*}{$\begin{array}{l}\text { Number of lost to } \\
\text { follow-up }\end{array}$} & \multicolumn{2}{|c|}{ Univariable models } & \multicolumn{2}{|c|}{ Multivariable models } \\
\hline & & HR (95\% Cl) & $P$-value & HR (95\% Cl) & $P$-value \\
\hline Gender & & & 0.74 & & \\
\hline Female & 273 & 1 & & & \\
\hline Male & 273 & $1.03(0.87-1.22)$ & & & \\
\hline Year of ART initiation & & & 0.001 & & $<0.0001$ \\
\hline$<2007$ & 117 & I & & I & \\
\hline $2007-2010$ & 173 & $0.98(0.78-1.24)$ & & I.00 (0.78-I.27) & \\
\hline $201 \mathrm{I}$ and after & 256 & $1.36(1.09-1.70)$ & & $1.65(1.30-2.11)$ & \\
\hline Initial clinical stage & & & $<0.000$ I & & 0.0024 \\
\hline$A, B / I, I I$ & 153 & I & & I & \\
\hline AIDS/III,IV & 184 & $1.38(1.11-1.71)$ & & $1.41(1.13-1.76)$ & \\
\hline Missing & 209 & $1.63(1.32-2.00)$ & & $1.41(1.13-1.77)$ & \\
\hline Initial CD4 cell count (cells/pL) & & & $<0.0001$ & & 0.0025 \\
\hline$\geq 350$ & 69 & 1 & & 1 & \\
\hline $200-349$ & 88 & $0.75(0.54-1.02)$ & & $0.80(0.58-1.10)$ & \\
\hline $100-199$ & 110 & $0.96(0.71-1.30)$ & & $0.94(0.69-1.29)$ & \\
\hline $50-99$ & 53 & $1.25(0.88-1.79)$ & & $1.26(0.87-1.82)$ & \\
\hline $0-49$ & 79 & $1.57(1.14-2.17)$ & & $1.49(1.06-2.08)$ & \\
\hline Missing & 147 & $1.31(0.99-1.75)$ & & $1.05(0.78-1.43)$ & \\
\hline Initial hemoglobin (g/dL) & & & $<0.0001$ & & 0.0021 \\
\hline$\geq 12$ & 34 & 1 & & 1 & \\
\hline $10-12$ & 76 & $1.48(0.99-2.22)$ & & $1.49(0.99-2.24)$ & \\
\hline $7.5-10$ & 71 & $1.80(I .20-2.7 \mathrm{I})$ & & $1.61(1.06-2.45)$ & \\
\hline$<7.5$ & 8 & $1.45(0.67-3.14)$ & & $1.32(0.61-2.90)$ & \\
\hline Missing & 357 & $2.33(1.64-3.32)$ & & $2.04(1.40-2.97)$ & \\
\hline First ART regimen & & & $<0.0001$ & & 0.029 \\
\hline $\mathrm{AZT}+3 \mathrm{TC} / \mathrm{FTC}+\mathrm{NVP} / \mathrm{EFV}$ & 159 & 1 & & I & \\
\hline D4T+3TC/FTC + NVP/EFV & 91 & $0.95(0.74-1.23)$ & & $1.05(0.79-1.38)$ & \\
\hline TDF $+3 T C / F T C+N V P / E F V$ & 91 & $1.23(0.95-1.59)$ & & I.08 (0.83-I.42) & \\
\hline Others/unknown & 205 & $1.71(1.39-2.11)$ & & $1.39(1.10-1.74)$ & \\
\hline BMI $\left(\mathbf{k g} / \mathbf{m}^{2}\right)$ & & & $<0.0001$ & & $<0.0001$ \\
\hline $18-25$ & 119 & 1 & & I & \\
\hline$<18$ & 56 & $1.48(1.08-2.03)$ & & $1.30(0.94-1.80)$ & \\
\hline$\geq 25$ & 32 & $0.86(0.58-1.27)$ & & $0.88(0.59-1.31)$ & \\
\hline Missing & 339 & $1.89(1.54-2.34)$ & & $1.95(1.54-2.47)$ & \\
\hline Total number of patients started ART in & & & 0.0004 & & $<0.000$ I \\
\hline 20I4-20I5 and still in care, in the facility & & & & & \\
\hline$<500$ & 161 & 1 & & 1 & \\
\hline $500-1000$ & 264 & $0.73(0.60-0.88)$ & & $0.96(0.77-1.19)$ & \\
\hline$\geq 1000$ & 121 & $0.64(0.51-0.82)$ & & $0.56(0.43-0.73)$ & \\
\hline
\end{tabular}

Abbreviations: ART, antiretroviral therapy; BMI, body mass index. 


\section{Publish your work in this journal}

HIV/AIDS - Research and Palliative Care is an international, peerreviewed open access journal focusing on advances in research in HIV, its clinical progression and management options including antiviral treatment, palliative care and public healthcare policies to control viral spread. The journal is included in PubMed. The manuscript man-

Submit your manuscript here: https://www.dovepress.com/hivaids---research-and-palliative-care-journal 